\title{
Revolución y diplomacia: el caso de la primera Junta de Quito (1809) ${ }^{1}$
}

\author{
Daniel Gutiérrez Ardila \\ Universidad París I Panthéon-Sorbonne, Francia \\ roquefresneda@yahoo.com.mx
}

\begin{abstract}
Resumen
El presente artículo es un análisis detallado del complejo programa de las políticas exteriores que se fijó la Suprema Junta de Quito en 1809. Igualmente, da cuenta de los diferentes medios a los que recurrieron las autoridades revolucionarias para ponerlo en práctica, y, por último, se concentra en las razones por las cuales sus ambiciosos proyectos se saldaron con un estruendoso fracaso. Para lograr estos objetivos, se han empleado documentos provenientes de diferentes archivos de España y América.
\end{abstract}

Palabras clave: Quito, independencia, siglo XIX, relaciones exteriores, juntas de gobierno.

\begin{abstract}
This article offers a detailed analysis of the complex foreign policy program of the Supreme Junta of Quito in 1809. It also examines the means used by the revolutionary authorities in order to put the program into practice, and the reasons of the failure of the ambitious projects. The article is based on the analysis of documents proceeding from different archives of Spain and Latin America.
\end{abstract}

Key words: Quito, independence, 19th century, foreign policy, junta, government.

\footnotetext{
${ }^{1}$ Este artículo es el resultado de la investigación titulada "La revolución en el extranjero. Nacimiento de la diplomacia en el Nuevo Reino de Granada 1808-1816", y ha sido posible gracias a una beca de Colfuturo. Deseo agradecer, especialmente a Federica Morelli por su atenta lectura y sus generosos comentarios. También a Annick Lempérière, Roberto Luis Jaramillo, Clément Thibaud, Jeanne Chenu, Georges Lomné, Geneviève Verdo, Véronique Hébrard y Sergio Mejía.
} 


\section{FRONTERAS}

de la historia

Vol.12 / 2007

\section{Introducción}

Todo gobierno insurgente se ve en la precisa obligación de establecer relaciones con el exterior. De ello depende no sólo la consecución de auxilios militares, sino también la creación de alianzas y pactos que permitan la pervivencia del nuevo régimen. En última instancia, el proceso que da origen a una nueva diplomacia culmina con el reconocimiento propiamente dicho por parte de las potencias, con el cual se sella el ingreso del Estado revolucionario al "concierto de las naciones".

El origen de las relaciones exteriores de las repúblicas hispanoamericanas ha sido poco estudiado. Existen numerosos libros que exploran con detenimiento la "diplomacia del reconocimiento", mas pocos autores han analizado en detalle los prolegómenos del proceso ${ }^{2}$. En efecto, entre los procuradores de antiguo régimen que solicitaban mercedes en Madrid a nombre de las múltiples corporaciones indianas y los primeros embajadores de los estados hispanoamericanos, hay un camino complejo y arduo, cuyas diversas etapas coinciden con los avatares de la revolución misma. Por ello es necesario ampliar el marco de análisis, explorando no sólo el establecimiento de relaciones con las potencias occidentales, sino también con los diferentes gobiernos provinciales que componían un virreinato o una capitanía general y que debían asociarse para crear un nuevo Estado (Gutiérrez, "La diplomacia"). En ese sentido, el estudio de las relaciones exteriores de la primera junta de Quito resulta fundamental. En primer lugar, porque fue una de las primeras instaladas en América, y en segundo término, porque a pesar de haber tenido una duración extremadamente corta (menos de tres meses), sus miembros diseñaron un sofisticado programa diplomático que constituye el fundamento de las relaciones exteriores del interregno neogranadino. Tal es el objeto del presente artículo.

\section{La revolución del 10 de agosto de 1809}

Tras haber dependido durante dos siglos de las autoridades de Lima, los territorios de la Audiencia de Quito pasaron a formar parte del Virreinato del Nuevo Reino de Granada, establecido definitivamente en 1739 (McFarlane 283313). Al producirse, pues, la invasión de España por los ejércitos napoleónicos, los tribunales de Quito tenían una influencia precaria que se extendía entre Buga y Guayaquil, es decir, sobre los corregimientos de Ibarra, Riobamba, Otavalo,

\footnotetext{
${ }^{2}$ Para el caso colombiano véanse, por ejemplo: Urrutia; Zubieta; Cavelier; Rivas.
} 
Ambato, Guaranda y Latacunga, y las gobernaciones de Cuenca, Mainas, Guayaquil y parte de la de Popayán (Deler; Phelan; Terán).

En un magnífico libro, Demetrio Ramos mostró cómo la subordinación a Santafé o Lima constituía una situación insoportable para los quiteños. En su lugar, éstos habían proyectado crear durante la presidencia del barón de Carondelet una capitanía general que debía incluir a Guayaquil, Popayán, el Chocó y Panamá. Esperaban así revertir los recortes hechos a su jurisdicción (Mainas y Guayaquil habían pasado a depender en lo militar de Lima; Tumaco, Atacames, La Tola y Limones habían sido agregados a Popayán) y contrarrestar las consecuencias de la apertura del cabo de Hornos, que había provocado la decadencia de sus manufacturas (Ramos cap. 4).

Así lo confirma el plan del capitán Juan Salinas, que fue redactado a principios de 1809 y preveía la creación de una Junta Provincial encabezada por el marqués de Selva Alegre. Las políticas económicas del nuevo gobierno debían incluir no sólo el desarrollo de la minería en Latacunga y el río Napo (donde las cuadrillas de negros se alimentarían de manatíes), sino también la exportación de textiles y la siembra de cacao en la costa chocoana. Con los retornos de aquel cultivo se haría el comercio con Lima y México, por lo que el puerto de La Tola adquiriría una importancia fundamental. Además, a él llegarían "baratísimos" los efectos de Europa introducidos desde Panamá (AGN, $H$ 6, ff. 68-71). Con su proyecto, el capitán Salinas no buscaba la deposición de las autoridades, sino tan sólo un remedio efectivo en caso de una hipotética subyugación de la Península o de una extinción total de la casa Borbón. Sin embargo, al enterarse del plan, el presidente Ruiz de Castilla ordenó el seguimiento de una ruidosa causa que llevó a la cárcel a miembros muy influyentes de la sociedad. Sin lugar a dudas, el hecho aumentó los recelos, ya de por sí considerables, que abrigaban las élites de la ciudad con respecto a sus gobernantes. No obstante, la legendaria torpeza con que se adelantó el proceso indica claramente que lo único que buscaban las autoridades era disuadir a ciertos individuos de emprender cualquier movimiento subversivo (AHR, FI 25, ff. 48-51v.).

La velada advertencia del presidente Ruiz de Castilla no tuvo el efecto esperado, antes bien, precipitó la revolución, que se produjo con orden y sin sobresaltos. El 8 de agosto numerosos vecinos de los cinco barrios de la ciudad designaron apoderados para que en su nombre procedieran a la modificación del gobierno (AHR, FI 25, ff. 4-7v.). Así representado, en la madrugada del 10, el pueblo de Quito destituyó a las autoridades y asumió la potestad suprema, pretextando el avance de los franceses y la huida de los miembros de la Junta 


\section{FRONTERAS}

de la fistoria

Central a Sevilla. Los revolucionarios, considerando que aquella corporación se hallaba extinguida, expirante o subyugada por el invasor, procedieron a evitar las consecuencias de la acefalía, siguiendo el ejemplo de las Provincias de España, y en especial el del Principado de Asturias. Erigieron así una junta que llamaron Suprema, la cual debía gobernar precaria e interinamente mientras se restituía Fernando VII al trono, o se trasladaba a América a ejercer su reinado (AGN, H 5, f. 609 y ss; "Confesión”).

La voluntad expresa de imitar los acaecimientos de la Península explica la adhesión de los revolucionarios a los principios cardinales del discurso patriótico (religión, rey y patria) que fueron invocados profusamente en los papeles del gobierno (Hocquellet). La influencia peninsular da cuenta, igualmente, de la proclamación de la soberanía que permitió a los quiteños no sólo dar tratamiento de majestad a la Junta Suprema, sino también deponer los magistrados legítimos, establecer tribunales, rebajar impuestos, extinguir estancos y aumentar los sueldos de las tropas ("Acusación" 44). Finalmente, el apego a los principios del levantamiento español permitía desvirtuar toda sospecha de parentesco con la revolución francesa. Tal preocupación es perceptible aun en la fecha escogida para la erección de la Junta, que invocaba la protección de San Lorenzo, y recordaba, en consecuencia, la batalla de San Quintín y el palacio del Escorial, centro del poder monárquico (Demélas 177).

En la madrugada del 10 de agosto los líderes quiteños crearon una milicia que llamaron falange, y un senado bicameral en reemplazo de la Audiencia. Así mismo, establecieron dos ministerios, confiando al Dr. Rodríguez de Quiroga el de Hacienda, Gracia y Justicia, y al licenciado Juan de Dios Morales el de Estado, Guerra y Relaciones Exteriores ${ }^{3}$. Por ser de primordial interés para este estudio, es necesario explicar con detenimiento qué entendían quiteños por negocios diplomáticos.

En primer lugar, el nuevo gobierno pretendía aprovechar la coyuntura para extender la influencia de la ciudad de Quito más allá de su distrito y fundar así un nuevo ente político que fuera independiente tanto de Lima como de Santafé. Según los cálculos de los revolucionarios, la autoridad de la Junta Suprema debía imponerse también a las provincias de Guayaquil, Panamá y Popayán ${ }^{4}$. En

\footnotetext{
${ }^{3}$ Además de Restrepo, constituyen la bibliografía básica sobre la revolución del 10 de agosto: Landázuri, "La independencia" y "Las primeras"; Torre; Rodríguez, "Las primeras" y La revolución.

${ }^{4}$ En el acta de instalación, los llamados diputados del pueblo declararon que la Junta Suprema debía ser completada por los representantes de los Cabildos de las provincias sujetas a Quito y por
} 
ese sentido, se proponían realizar los planes concebidos desde los tiempos del barón de Carondelet que, como se ha visto, habían sido reivindicados en febrero por el capitán Salinas.

¿Ambicionaban los quiteños conformar un ente político con cartageneros y antioqueños? La hipótesis es corroborada por serios indicios, de los cuales el principal son las claras conexiones que existían con unos y otros. En efecto, Cartagena era el principal puerto del Reino y por él entraban las mercancías europeas. Existían, pues, relaciones mercantiles muy sólidas y de vieja data. Especialmente importante había sido la conducción del situado, es decir, de los 250 mil o 300 mil pesos de plata con que contribuía anualmente la Presidencia de Quito al sostenimiento de la plaza de Cartagena. Dicha conducción se remataba, y el situadista remitía por su cuenta y riesgo los caudales a Popayán en forma de efectos y frutos de la tierra, tras lo cual, y ya con doblones de oro, pasaba a Cartagena a adquirir mercancías ${ }^{5}$.

En cuanto a Antioquia, debe tenerse en cuenta que el presidente Juan Antonio Mon y Velarde - uno de los grandes impulsores del camino de Malbuchohabía sido previamente visitador de aquella provincia. En su traslación desde Santafé, donde había sido oidor, lo acompañó un tal Juan de Dios Morales, joven antioqueño que había estudiado derecho en el Colegio de San Bartolomé y había pasado a Quito movido por la esperanza de recibirse de abogado y labrar fortuna. Tras culminar la práctica de rigor, su benefactor lo nombró secretario interino de la Presidencia, empleo que volvería a ocupar, ya en propiedad, durante el gobierno del barón de Carondelet (AGI, $Q 234$ ). Es, pues, más que probable que el abogado hubiera cumplido un papel clave en el establecimiento de relaciones comerciales directas entre Quito y Antioquia. Efectivamente, desde 1804 Carondelet, noticioso del proyectado camino al Atrato, había incitado a las autoridades de dicha provincia a promover el intercambio de harinas y bayetas por oro (AGI, $S F$ 960). Sus instancias no fueron inútiles y las negociaciones tenían curso, cuando menos, desde comienzos de 1807 (AHA, I, 816, doc. 12834, f. 80v.).

\footnotetext{
"las que se unan voluntariamente a ella en lo sucesivo, como son Guayaquil, Popayán, Pasto, Barbacoas y Panamá, que ahora dependen de los virreinatos de Lima y Santafé, las cuales se procurarán atraer".

Esta costumbre que permitía dinamizar la economía de la provincia de Quito había sido torpemente abolida por el virrey de Santafé quien ordenó que, en adelante, la remisión se hiciera en metálico. Según el barón de Carondelet, esa era una de las causas de la decadencia y miseria del gobierno a su mando (AGI, $Q 252$ ).
} 


\section{FRONTERAS}

de la historia

¿Era la designación del licenciado Juan de Dios Morales como ministro de Estado y Relaciones Exteriores una mera casualidad, o se trataba también de un guiño a sus compatriotas? ¿Existía acaso una un trato secreto con sus amigos y familiares antioqueños? ¿Era disimulado partícipe del proyecto su tío y antiguo maestro Félix de Restrepo, que residía en Popayán y era considerado como una de las eminencias de Antioquia? (AGI, $Q 235$ ).

Confirman también la hipótesis de la proyectada unión de Quito con Antioquia y Cartagena las denuncias hechas en enero de 1811 por el diputado de la Provincia de Santafé al vicepresidente de la Junta Suprema de la misma ciudad. Manuel Bernardo Álvarez aseguró en aquella ocasión tener noticia de la existencia de un plan de alianza entre Quito, Popayán, Antioquia, Chocó, Cartagena, Santa Marta, Riohacha y Mariquita (AGN, $H$ 15, ff. 430-433v.). Estas denuncias, independientemente de sus fundamentos, revelan un gran temor de los capitalinos que bien podía provenir de los proyectos secretos de la Junta de 1809.

Sea como fuere las tentativas de expansión de la Junta de Quito implicaban arduas negociaciones no sólo con los cabildos de esa jurisdicción ideal, sino también con los gobiernos del Nuevo Reino y con el Perú, que habían de padecer la desmembración de sus territorios. En efecto, los juntistas estaban convencidos de que su ejemplo sería seguido por todo el continente: el marqués de Villa Orellana aseguraba tener noticias ciertas de que se produciría un movimiento simultáneo, y el licenciado Juan de Dios Morales, que compartía las mismas esperanzas, confirmó sus sospechas, al recibir la noticia de los sucesos de La Paz y Chuquisaca ("Carta").

Sin embargo, los negocios exteriores de la Junta de Quito no pueden reducirse a las gestiones para extender su territorio. En primer lugar, en caso de perpetuarse el poder napoleónico, sería necesario firmar alianzas y establecer relaciones comerciales con las potencias extranjeras. En segundo lugar, la resistencia de las provincias de España y la erección de juntas provinciales soberanas habían convertido a la nación española en un conjunto de "estados federativos" (AHR, FI 25, ff. 179v.-180). En consecuencia, la subsistencia de las relaciones

\footnotetext{
${ }^{6}$ En carta a don Javier de Ascázubi el 21 de septiembre de 1809, Morales daba un plazo de dos meses para que el movimiento revolucionario contagiara al continente entero (AGN, $H$ 6, f. 719). En abril del año siguiente el fiscal Arechaga referiría en su acusación que los revolucionarios solían suponer públicamente haberse erigido juntas no sólo en Lima y Santafé, sino también "en todas las demás Provincias de ambas Américas". Véase: "Acusación” (43).
} 
imperiales implicaba la creación de nuevos lazos políticos entre los diferentes reinos que asumieran la autoridad suprema.

\section{La ardua búsqueda de la obediencia}

Tan pronto como se posesionó en su cargo, el marqués de Selva Alegre, presidente de la Junta Suprema, dirigió oficios a los ayuntamientos de las provincias circunvecinas, anunciándoles las últimas ocurrencias, solicitando el reconocimiento del nuevo gobierno y excitándolos a despachar diputados que los representasen. Dichos oficios revisten el mayor interés porque constituyen la primera tentativa hecha por los quiteños para imponer a territorios ajenos a su distrito la soberanía interina que acababan de proclamar.

La comunicación remitida por Selva Alegre al cabildo de Popayán ilustra la estrategia política empleada por los revolucionarios para conseguir la adhesión de los gobiernos fronterizos. Según el presidente de la Junta Suprema, la secular dependencia en la administración de justicia y la imposibilidad de prescindir de las relaciones comerciales que aseguraban su subsistencia, hacían necesaria la adhesión de la provincia al nuevo gobierno. Sin embargo, no sólo los lazos históricos y económicos imponían la reunión: Selva Alegre recordaba al ayuntamiento la imposibilidad en que se hallaba Popayán de mantener su independencia en medio de "dos Reinos superiores en fuerzas y recursos" y se esforzaba en convencerlo de las ventajas que podía esperar uniéndose a Quito más bien que a Santafé (AHR, FI 25, f. 38). La idea de un gobierno provincial autónomo podía seducir la mente de los patricios payaneses y era necesario combatirla, del mismo modo que la peligrosa tentación de adherir a la Junta que se erigiera en la capital del Nuevo Reino. En el oficio a Cuenca no hay iguales raciocinios, pero cabe suponerlos en el dirigido a Guayaquil, cuya obediencia podía ser perturbada por veleidades autonomistas y por la atracción ejercida por Lima (AGN, $H$ 4, f. 508).

La argumentación utilizada por Selva Alegre en contra de la creación de pequeñas soberanías es digna de interés, pues remite a la necesidad de crear gobiernos en América lo suficientemente fuertes para contrarrestar las ambiciones de sus vecinos. Con el fin de evitar los desórdenes y las guerras era necesario constituir en el continente un sistema de equilibrio, similar al descrito con tanto entusiasmo por los publicistas europeos (Belissa). En ese sentido la adhesión de Popayán era fundamental para Quito, que — según afirmó Selva Alegre en el oficio citado - se encontraba en la necesidad de "arreglar sus límites proporcionándose una posición fronteriza capaz de consultar a su mayor 


\section{FRONTERAS}

de la historia

seguridad". En cuanto a la pugna con Santafé y Lima, los miembros de la Junta Suprema esperaban salir victoriosos seduciendo a los pueblos con prebendas y abolición de impuestos.

Los documentos demuestran que la adhesión de Popayán era prioritaria, sin duda en razón de sus establecimientos mineros. No en vano las autoridades revolucionarias nombraron siete payaneses en el Senado ${ }^{7}$, esto es, la mitad de los miembros del organismo creado en reemplazo de la Audiencia (AGN, H 6, f. 569). José María Tejada, designado capitán de milicias por los juntistas, escribiría el 21 de agosto un par de cartas a familiares suyos en Popayán en las que recordaba este acontecimiento significativo, antes de concluir diciendo:

[...] esperamos que esa ciudad se una con ésta más bien que a Santafé, que la ha tiranizado por cuantos medios ha habido, ya procurando destruir las casas de moneda, ya acomodando en los empleos a los moscas, y por todas estas razones y por la generosidad con que se maneja esta Suprema Junta deben todos unirse a ella. (AGN, $H$ 6, ff. 545-546 y 549-550v.)

En las numerosas cartas que payaneses influyentes, favorecidos con los nuevos empleos, escribieron en aquellos días a sus familiares y amigos, es perceptible también la intención de estimular la rivalidad con Santafé como medio efectivo para lograr la reunión de Popayán (AGN, H 6, f. 544 y ss.).

La adhesión de Guayaquil, Cuenca y Barbacoas intentó conseguirse también con el apoyo de las correspondencias particulares ${ }^{8}$. Previendo quizás la resistencia de Popayán, se procuró atraer a los mineros de Barbacoas con la erección de una gobernación independiente, la extinción del estanco de aguardiente, los socorros de fierro y acero, y las promesas de mejoras en el comercio terrestre y marítimo. Esta oficiosa campaña de propaganda epistolar incluía copias de las resoluciones de la Junta Suprema y se esforzaba en demostrar que la del 10 de agosto había sido una revolución sin sangre, respetuosa de la religión y el vasallaje debido a Fernando VII.

\footnotetext{
${ }^{7}$ Éstos eran: Quijano, Murgueitio, Tejada (nombrado en reemplazo del también neogranadino Víctor de Sanmiguel, quien declinó el nombramiento), Escobar, Cabal, González y Tenorio. Para reemplazar a este último, que terminó fugándose, fue nombrado Pedro de Quiñones y Cienfuegos, natural de Barbacoas.

${ }^{8}$ L. F. Borja publicó 17 interesantes cartas dirigidas a Barbacoas tras la instalación de la Junta Suprema en el Boletín de la Sociedad Ecuatoriana de Estudios Históricos Americanos (3.6 s. f.: 419-43). Las cartas destinadas a Guayaquil se encuentran en AGN ( $H$ 5, f. 120 y ss).
} 
Los vocales de la Junta de Quito confiaban en que la noticia de su establecimiento generaría una adhesión espontánea en las provincias circunvecinas. Tales esperanzas parecieron bien fundadas durante los primeros días, cuando reconocieron el nuevo gobierno las villas de Riobamba e Ibarra, los corregimientos de Otavalo, Latacunga, Ambato, Guaranda y Alausí; la tenencia del Puerto de La Tola y la Provincia de Los Pastos (AHR, FI 25, f. 188).

Sin embargo, los revolucionarios subestimaron dos factores esenciales que a la postre contribuirían poderosamente en su ruina: las rivalidades provinciales y la influencia de los funcionarios reales. En cuanto a lo primero, todo indica que la constitución de la Junta Suprema fue sentida como una amenaza por los patricios de Popayán, Cuenca y Guayaquil, quienes temían que la preponderancia de Quito se consolidara en detrimento de sus propios intereses. Los primeros nombramientos emanados del nuevo gobierno - que recayeron en miembros de las familias más conspicuas de esta ciudad - acrecentaron sin duda los recelos (Morelli 62). En lo referente a los magistrados, es preciso señalar que los gobernadores Cucalón, Aymerich y Tacón, y el obispo Andrés Quintián, dieron prueba durante la crisis de una capacidad poco común y lograron contener con relativa facilidad el contagio revolucionario. Recurrieron para ello al estrecho control de los ayuntamientos, a los preparativos militares, a la suspensión de las comunicaciones y a la detención de los familiares de los juntistas (AGN, $H$ 4, ff. 511-514; AHR, FI 25, ff. 39-44). A mediados de octubre el obispo de Cuenca se ufanaría, en carta al virrey del Perú, de haber presenciado todas las sesiones del cabildo desde el comienzo de la revolución "asistiendo a [la redacción de] sus actas, rectificándolas, [y] persuadiendo con expresiones enérgicas a los Vocales a sostener la fidelidad jurada a su rey" (“Documentación” 259).

Precisamente, el cabildo de Cuenca, al recibir la invitación del marqués de Selva Alegre, acordó remitir sendos diputados a las ciudades de Loja y Guayaquil con el fin de que dieran cuenta de las novedades ocurridas y solicitaran auxilios militares. El cometido del cabildo era adelantarse a los recursos seductivos de Quito y conformar un anillo defensivo para contener sus ataques. Para dichas misiones fueron nombrados, respectivamente, José María de Landa y Ramírez, secretario del obispo, y Joaquín de Salazar y Lozano. La medida fue tan efectiva que el 21 de agosto el corregidor de Loja se había comprometido ya a unir sus fuerzas a las de Cuenca, e incluso había remitido a aquella ciudad los pobres refuerzos que le permitían sus circunstancias: 60 milicianos inexpertos, sin vestidos y desarmados (AGN, $H 4$, f. 845). 


\section{FRONTERAS}

de la historia

Las noticias según las cuales en Cuenca, Guayaquil y Popayán se reputaba por sediciosa y criminal la Junta Suprema llenaron de consternación a los miembros del gobierno revolucionario. La confianza en una adhesión espontánea de las provincias confinantes, que había subsistido durante el primer mes, se desplomó de repente sin haber producido ningún efecto favorable. Ante las graves amenazas de guerra civil, se imponía una revisión de la política exterior de la Junta: el recurso de la correspondencia resultaba en adelante insuficiente. El licenciado Juan de Dios Morales se consagró entonces al despacho de tres "legaciones", destinadas a los gobiernos disidentes. Para cada una de estas misiones fueron escogidos dos diputados a quienes se proveyó de las credenciales, poderes e instrucciones correspondientes.

El 7 de septiembre, por ejemplo, Morales redactó el siguiente oficio dirigido a los cabildos de Pasto y Popayán:

\section{I. A.}

Habiendo la Suprema Junta que gobierna interinamente este Reino, como representativa de nuestro legítimo soberano el señor don Fernando VII, decretado una legación cerca de V. S. M. I., nombrando para desempeñarla al excelentísimo señor don Manuel Zambrano y al señor don Antonio Texada, les doy ésta como primer secretario de estado de su majestad para que en su virtud se les preste toda fe y crédito y pueda V. S. M. I. tratar con ambos los negocios a que son destinados. (AGN, $H$ 5, ff. 259, 276 y 682.)

Estas credenciales fueron otorgadas, como es notorio, a nombre de Fernando VII por la Suprema Junta. Ellas demuestran, en consecuencia, el surgimiento de una diplomacia dentro de la misma monarquía, cuyos propósitos eran mantener la unidad de la nación y preservar los derechos del rey durante la crisis. La legación de Zambrano y Tejada debía, por lo tanto, disipar las falsas acusaciones de rebelión, establecer la paz y buscar la unión y alianza de la provincia de Popayán con el titulado Reino de Quito (AGN, $H$ 5, f. 272) ${ }^{9}$.

Siendo el derecho de embajada inseparable de la soberanía, es comprensible que la Junta Suprema despachara representantes. Pero, al ser éste un comercio practicado tan sólo entre soberanos (Wicquefort 69), ¿cómo explicar que el

\footnotetext{
${ }^{9}$ El Marqués de Selva Alegre escribió Manuel Zambrano el 15 de septiembre informándole que el senador Tejada no podría acompañarlo en su misión. Al cabildo de Pasto envió una copia del oficio, "para su inteligencia y a fin de que no extrañe la falta del Ministro". En efecto, Tejada, a quien se le había ofrecido antes la diputación a Guayaquil, se excusó por reputar el encargo sedicioso (AGN, $H$ 6, f. 367).
} 
gobierno quiteño dirigiera legaciones a provincias que no habían hecho la revolución? La explicación se encuentra indudablemente en el "Manifiesto al público" expedido por la Junta de Quito para dar satisfacción de sus procedimientos. Según este documento, al hallarse reducido el mando de la Junta Central a Andalucía sola, "no reunía ya en sí la voluntad general". Los triunfos militares de los franceses habían provocado la cesación de los representados y, por lo tanto, había prescrito su representación. Los vocales de la Junta Central no podían a partir de ese momento representar a la nación. De aquí se desprendía una consecuencia de primerísima importancia para América, pues "habiendo cesado el aprobante de los Magistrados, han cesado también éstos sin disputa en sus funciones, quedando por necesidad, la soberanía en el pueblo" (Monsalve 1: 328-30). Así, las legaciones enviadas por la Junta Suprema de Quito se dirigían a los cabildos de Popayán, Guayaquil y Cuenca, representantes de sus respectivos pueblos, que en virtud de las circunstancias habían reasumido la soberanía.

De este modo puede explicarse también la doble acreditación de los comisionados despachados por las autoridades revolucionarias. En efecto, el cabildo de Quito había otorgado también credenciales a los enviados a la gobernación de Popayán. Lo mismo sucedería con la legación a Cuenca, cuyos diputados, luego de recibir las credenciales expedidas por la Junta Suprema, las pidieron también a los ayuntamientos secular y eclesiástico. En cuanto "cuerpos reconocidos", estas corporaciones podían otorgar una legitimidad indisputable a las misiones, en caso de que la Junta Suprema despertara suspicacias sobre su legitimidad. Así se explica esta anomalía que podría parecer en primera instancia una redundancia inútil ${ }^{10}$.

El 23 de septiembre ya se hallaba en Tulcán el diputado Zambrano. Desde allí y por conducto de José Ramón Ayala, cura del pueblo de Mallama, pidió audiencia y envió sus poderes y credenciales al cabildo de Pasto. A más de lo anterior, solicitó pasaportes para sí mismo y para su comisión de honor, así como una persona de condición equivalente a la suya, a guisa de rehén (AGN, $H$ 5 , f. 280).

\footnotetext{
10 "En virtud de lo expuesto en esta credencial, no duda este cabildo que vuestra señoría admitirá y tratará con todo el honor y decoro que se merece el dicho señor diputado, así por su persona, como por su carácter, conferenciando con él sobre el arreglo y dirección de todos los puntos y negocios concernientes a la buena armonía y bien estar de estas provincias para evitar los daños que causan los recelos y disturbios, al real servicio y bien público; que son los sagrados objetos a cuya consecución debemos propender generalmente" (AGN, H 5, f. 278; H 6, f. 349).
} 


\section{FRONTERAS}

de la fistoria

El cabildo de Pasto respondió dos días después con evasivas y zalamería: en una carta en que daba trato de "Excelencia" al diputado quiteño, le aseguraba que por pender del gobierno de Popayán, no podía el ayuntamiento resolver cosa alguna. Entre tanto, se comprometía a dispensar a Ayala la misma consideración y atenciones que al enviado mismo, cuidándose de no quebrantar en modo alguno el derecho de gentes. En realidad, el eclesiástico fue desde entonces custodiado por seis hombres, y se le negó toda comunicación ${ }^{11}$. Aparentemente, fue esta conducta de las autoridades de Pasto la que provocó la entrada de las tropas quiteñas, el mismo día, al territorio de la gobernación de Popayán ${ }^{12}$. El 30 de septiembre, es decir, cuando ya se había producido el rompimiento, el cabildo de esta ciudad, decidió impedir la entrada de los enviados de Quito por considerarla peligrosa y contraria a la pragmática de Carlos III (ley $8^{\mathrm{a}}$, tít. 15 , lib. $8^{\circ}$, art. 18 de la Recopilación de Castilla) que prohibía no sólo la admisión de los representantes de los sediciosos, sino también el que éstos pudieran capitular con los jueces (AGN, H 5, ff. 260-263, 282-293, 800-801).

La política exterior de los quiteños en el Nuevo Reino resultó ser, pues, un rotundo fracaso. ¿Qué sucedió con las dos legaciones restantes? A Guayaquil fueron destinados como diputados el marqués de Villa Orellana y José Fernández Salvador ${ }^{13}$. El 14 de septiembre desde Guaranda escribieron temerosos al gobernador Bartolomé Cucalón anunciándole la misión que se les había encomendado y que estaba destinada, según explicaron, a buscar la reconciliación entre ambas provincias. Por tal motivo, y por ser tan ajenos a su carácter los medios de "la seducción y el engaño", le solicitaban salvoconductos para poder trasladarse tranquilamente a la ciudad de Guayaquil. El 19 de septiembre el gobernador respondió con sequedad a las insinuaciones de los enviados, limitándose a asegurarles que se les permitiría la entrada a la provincia y que se les trataría "sin impropiedad". Ante semejantes garantías no es sorprendente que la misión se haya deshecho: el marqués de Villa Orellana, intimidado, detuvo su viaje, en tanto que Salvador renunció a la comisión y al empleo de senador, tras lo cual se dirigió a Guayaquil, donde hizo

${ }^{11}$ El 26 de septiembre, en oficio dirigido al gobernador de Popayán, Tomás de Santacruz se burlaba del "embajador de comedia" de los quiteños, y se jactaba de haberle respondido con "excelencias de farsa" para ver si por ese medio lograba reunir fuerzas.

${ }^{12}$ Las tropas quiteñas se hallaban en Tulcán desde antes de la llegada del diputado. Preocupado por no disponer de armas ningunas — sólo contaba con piedras y arados-, el corregidor de la provincia de Los Pastos había logrado pactar una tregua con el comandante del enemigo, mientras se definían los resultados de las diputaciones.

${ }^{13}$ El cargo había sido ofrecido con anterioridad, como se ha visto, al senador Tejada y a Francisco Javier de Salazar, quien resistió el nombramiento, a pesar de los 1.000 pesos que se le ofrecieron (AGN, $H$ 6, f. 320 v). 
"declaraciones circunstanciadas acerca del estado de los rebeldes, sus hechos y armamento" (AGN, $H$ 5, ff. 449, 500, 550-551; H 11, ff. 284-316) ${ }^{14}$.

La última de las legaciones despachadas por el gobierno de Quito iba dirigida, como se ha dicho, a Cuenca. Como diputados de ella habían sido escogidos Salvador Murgueitio y el regidor Pedro Calisto y Muñoz. Antes de partir hacia su destino ambos recibieron instrucciones secretas de Selva Alegre en las que se les ordenó hacer caso omiso de las comunicaciones de Juan de Dios Morales y se les mandó imponer sus buenos oficios para lograr la restitución del presidente Ruiz de Castilla. De camino para Cuenca, Murgueitio creyó necesario, además, otorgar en el campo y ante varios testigos una escritura de renuncia en la que declaró no haber tomado parte en las novedades de Quito más que forzado y por temor (AGI, $Q$ 269; AGN, $H$ 6, f. 350v.). Contrario a lo que parece, el fin buscado por Selva Alegre y Murgueitio con estos documentos era precaverse de las prisiones y embargos, en un contexto en el que se vislumbraba ya la ruina de la Junta Suprema. En efecto, ninguno de los dos dudaría en tomar parte activa en la revolución del año siguiente.

El 13 de septiembre se hallaban los diputados en Riobamba y desde allí escribieron al gobernador y al obispo, informándoles el objeto de su misión y solicitándoles una escolta que garantizase su seguridad y los pusiese "a cubierto de la gente torpe y ruda". Sin embargo, las autoridades se negaron a reunirse con los enviados pretextando que la fermentación popular hacía imposible su entrada en la ciudad ("Oficio").

Mientras se adelantaban las negociaciones por vía epistolar, los disputados informaban a su comitente y recibían a cambio instrucciones precisas firmadas por Selva Alegre y el ministro Morales. Las del 25 de septiembre, que se conservan en Bogotá, permiten saber con exactitud a qué se reducían los buenos oficios de los ministros. La preocupación mayor de los quiteños era evitar el desencadenamiento de la guerra y propiciar la unión. Para que ello fuera posible debían desvanecerse las acusaciones de rebeldía e insurgencia, insistiendo en los puntos esenciales que habían motivado la creación de la Junta: "fidelidad à Dios, al Rey y a la Patria".

Sordos ante las protestas de rectitud y sinceridad de la Junta, el obispo y el gobernador de Cuenca insistían en despreciar las conferencias que se les

\footnotetext{
${ }^{14}$ Una vez finalizados los días de la Junta de Quito, y en premio a su lealtad, José Salvador sería nombrado por Ruiz de Castilla corregidor interino de la villa de Riobamba.
} 


\section{FRONTERAS}

de la historia

brindaban, negándose a imponerse a fondo del "sistema político" fundado en Quito. La resistencia a recibir una diputación honrosa y legítima sólo podía explicarse, según Selva Alegre, por el criminal interés de romper "las relaciones estrechas de patriotismo y dependencia harmónica". En cuanto a la Junta Central, que era el punto más arduo de desacuerdo, el marqués indicaba a los diputados que el gobierno de Quito había de reconocerla siempre que ella existiera políticamente, es decir, mientras se mantuviera "en el mismo pie de libertad y representación legítima con que fue constituida para depositaria de la real autoridad". Así pues, el nuevo gobierno nunca había recurrido para su erección al falso supuesto de la extinción de la Junta Central. Sin embargo, Selva Alegre encarecía a los comisionados insistir en la justicia de recelar la total subyugación de la Península, peligro inminente, teniendo en cuenta las noticias llegadas de Europa. En ese sentido, los pasos dados por Quito tendían tan sólo a evitar que Bonaparte o cualquier otra autoridad obligara a los pueblos de América a seguir el trastorno general y a precipitarse en la ruina de España.

El licenciado Juan de Dios Morales pedía a los diputados subrayar la inexistencia política de la Junta Central añadiendo a las reflexiones del marqués que los reinos de la Península subyugados por los franceses carecían por ello de la representación que habían tenido antes de la invasión. En caso de que el obispo y el gobernador recurrieran al disparate de decir que los individuos que huyeron a Sevilla retenían la representación de los países conquistados, Murgueitio y Calisto debían hacerles ver que era absurdo suponer que "faltando el representado subsistiera el representante".

Según Selva Alegre, de continuarse negando los respectivos salvoconductos para adelantar las conferencias públicas, los comisionados quiteños debían proponer, como último medio de conciliación, que el cabildo, el obispo y el gobernador de Cuenca diputaran personas de su satisfacción para tratar libre y seguramente en Alausí o en cualquier otro punto de la frontera (AGN, $H$ 5, ff. 713-717v.).

Estos recursos no merecieron atención, por lo que la legación a Cuenca fracasó, del mismo modo que las dirigidas a Guayaquil y la gobernación de Popayán, sin que se hubiera dado siquiera una audiencia pública. El regidor Pedro Calisto, pocos días después, se unió a las autoridades regentistas y trabajó activamente para disolver el gobierno revolucionario. Murgueitio, entre tanto, desempeñó un destacado papel en la contrarrevolución en Riobamba y, particularmente, en la destitución del corregidor Javier Montúfar, hijo del marqués de Selva Alegre (AGI, $Q 269$ ). 


\section{La fallida confederación de soberanías interinas}

Al tiempo que eran enviadas las primeras comunicaciones a las provincias confinantes, Selva Alegre remitía oficios al virrey del Nuevo Reino y al Cabildo de Santafé. Al primero explicaba brevemente las novedades ocurridas el 10 de agosto y los fundamentos de la creación de la Junta Suprema. A continuación, considerando la intención del nuevo gobierno de conservar ilesos los derechos del rey hasta que éste estuviera en aptitud de regir el Reino de Quito, lo exhortaba a abstenerse de tomar cualquier providencia susceptible de causar un derramamiento de sangre (AHR, FI 25, f. 9).

La comunicación al Cabildo de Santafé, entre tanto, tenía por objeto invitar a sus miembros a hacer causa común con el gobierno revolucionario en la defensa de la religión, los derechos del rey y la libertad de la nación. Si se tiene en cuenta que el presidente de la Junta Suprema adjuntó una copia del impreso titulado "Manifiesto al público", se comprende fácilmente que su ofrecimiento era en realidad un llamado a deponer al virrey y los oidores y a establecer un gobierno interino. En efecto, en dicho papel no sólo se aseguraba que la Junta Central había perdido la representación política, sino que además se acusaba a los funcionarios reales en América de negligencia e inacción frente a las empresas de Napoleón. Habiendo sido subyugada casi toda la Península, los reinos americanos, declarados partes integrantes de la nación, no podían reconocer un gobierno tan defectuoso, y se veían en la necesidad de reasumir sus derechos ("Manifiesto").

Con el fin de evitar la anarquía, la Junta de Quito proponía pues, claramente, la creación de una serie de gobiernos provisionales siguiendo las lecciones del modelo español. Santafé y Lima, en su condición de capitales virreinales, tenían derecho a erigir juntas supremas, del mismo modo que México, Caracas, Guatemala, La Habana, Santiago y Buenos Aires. ¿Enviaron los quiteños invitaciones similares a estas capitales? La presunción es válida aunque no haya rastros de tales comunicaciones en los archivos. Quizás los revolucionarios pensaban hacerlo, mas no alcanzaron a realizar sus planes por la temprana caída de la Junta. Esta hipótesis parece sensata: la constitución de gobiernos en Lima y Santafé, por su peligrosa vecindad, era más urgente para los quiteños que la de otros reinos americanos.

Sea como fuere, existe un papel dado a la imprenta por Manuel Rodríguez de Quiroga, titulado precisamente Pueblos de América. En él, el ministro de Gracia y Justicia impelía al continente entero a seguir el ejemplo de Quito para crear 


\section{FRONTERAS}

de la historia

"un baluarte inexpugnable contra las infernales empresas de la opresión y la herejía". La confederación americana propuesta por los revolucionarios del 10 de agosto debía ser pues, en principio, una alianza defensiva contra el "tirano de la Europa" (AHR, FI, 25, f. 134).

Selva Alegre reanudó sus votos de alianza los días 20 y 21 de agosto en las comunicaciones que dirigió a los cabildos de Santafé, Lima y Cartagena. De nuevo, aunque de manera aún más explícita, en nombre de la Junta Suprema, el marqués solicitó la creación de una confederación para defenderse del enemigo común y sostener al rey y la nación ${ }^{15}$.

El ayuntamiento de Santafé recibió el oficio del gobierno revolucionario de Quito al mismo tiempo que otro del cabildo de Popayán en el cual declaraban la guerra a los insurgentes. En consecuencia, y con el fin de decidir los medios más adecuados para remediar la situación, instó al virrey a convocar una junta de todos los cuerpos, a semejanza de la que había tenido lugar para recibir al enviado de Sevilla en septiembre del año anterior (AGI, SF 746) ${ }^{16}$. La asamblea fue concedida y tuvo lugar el 6 de septiembre, mas por ser muy concurrida y haber disonancia de opiniones no se pudo llegar a ningún acuerdo. En efecto, con gran escándalo escucharon ese día las autoridades al asesor del Cabildo pedir el retiro del aumento de tropa que hacía guardia al virrey por considerarlo extraordinario y opresivo. Así mismo, vieron con asombro la solicitud de garantía que se requirió expresamente por algunos asistentes para "no poder ser molestados en sus personas y bienes por nada de cuanto dijesen" (AGN, H 5, doc. 131). Finalmente, un oidor de la audiencia de Quito que se hallaba a la sazón en Santafé llegó incluso a afirmar que "no estaba calificada la criminalidad" de los creadores de la Junta Suprema (AGN, $H$ 5, ff. 243-245). Por falta de consenso la asamblea quedó, pues, solemnemente prorrogada. No obstante, el tenor de las declaraciones de la primera sesión y las advertencias de algunos eclesiásticos tentaron al virrey a suprimirla y sólo cambió de parecer a instancias del Real Acuerdo.

Siguiendo sus instrucciones, Amar y Borbón, al inaugurar la nueva junta el 11 de septiembre, advirtió que sólo se debatirían allí dos puntos: el primero, de carácter deliberativo, tocante a la manera en que debía contestar el Cabildo de

\footnotetext{
${ }^{15}$ Las comunicaciones de la Junta a Santafé y Lima se encuentran en AGN ( $H$ 5, ff. 671 y 896, respectivamente). Véase también AHR (FI 25, f. 26). El oficio dirigido a Cartagena es mencionado por J. Jijón y Caamaño (37) y Gabriel Jiménez Molinares (51-59).

${ }^{16}$ Hay también al respecto un interesante documento firmado por José Acevedo Gómez y publicado por Eduardo Posada en el Boletín de Historia y Antigüedades (15.192 s. f.: 746).
} 
Santafé a la Junta de Quito, y el segundo, de carácter consultivo, relativo a los medios que debían adoptarse para sujetar a los rebeldes. La medida provocó las protestas del procurador, quien manifestó que si la Junta había tenido voto deliberativo el año anterior para reconocer a la de Sevilla como soberana, con mayor razón debía tenerlo para evitar la guerra civil. Las discusiones, no obstante, se llevaron a cabo y en su curso dos facciones se diferenciaron claramente: la de quienes propusieron "las vías de la paz y la negociación" y la de aquellos que se manifestaron a favor de "medidas hostiles y destructoras" Realizada la votación resultó que la mayor parte de los asistentes (33 de ellos) estaba a favor de que se erigiese una junta en la capital compuesta por los diputados de las provincias y presidida por el virrey. Juzgábase que por ese medio se haría ver a los quiteños la precipitación con la que habían actuado, y esperábase que el ofrecimiento de garantías y la invitación a remitir un diputado bastasen para restablecer la unidad. Las autoridades no sólo despreciaron estas medidas, sino que, además - y a pesar de las repetidas solicitudes del Cabildo de Santafé-, se negaron a extender las actas de las juntas por reputar algunas de las opiniones allí expresadas de "revolucionarias y subversivas"".

José Ignacio de Pombo también intervino en la polémica escribiendo desde Cartagena una carta al virrey, en la que lo exhortaba a agotar los recursos de conciliación antes de emprender cualquier acción violenta. En su opinión, lo más adecuado era despachar una comisión de "ministros de paz", compuesta al menos de tres sujetos de carácter, que tuvieran distintas profesiones y fueran de "conocida probidad, prudencia, moderación, talento e instrucción en materias políticas". Los comisionados debían dirigirse a Quito sin aparato militar, para ofrecer en nombre del rey y de la Junta Central perdón general y olvido de lo pasado, con las seguridades convenientes. Para el desempeño de tan delicada misión Pombo proponía al mariscal de campo Antonio de Narváez, al oidor Francisco de Cortázar y al coronel de milicias de Panamá Juan Domingo de Iturralde. A éstos podían unirse un ministro de la Real Hacienda, como Luis Eduardo Azuola o Felipe Vergara, y un particular distinguido que tuviera conocimientos y conexiones. José Ignacio de Pombo, que era un comerciante muy influyente, se ofrecía por ello a participar en la mediación. Finalmente, aconsejaba que la secretaría de dicha comisión fuera ejercida por un abogado

\footnotetext{
${ }^{17}$ Véase el "Suplemento al Diario Político número 6" en Martínez y Ortiz. Véase también Padilla (29-32); Palacio (43).

${ }_{18}$ Acta del Consejo de Regencia y documento de Acevedo Gómez. Así mismo, consúltense las importantes "Memorias" de José María del Castillo y Rada, publicadas por Eduardo Rodríguez Pineñerez (80) y la intervención en la junta de José Gregorio Gutiérrez —a la sazón síndico procurador general de Santafé-, incluida en la obra de Ignacio Gutiérrez Ponce (47).
} 


\section{FRONTERAS}

de la fistoria

ilustrado y versado en los negocios políticos como Frutos Joaquín Gutiérrez (AGN, $H$ 5, f. 248-251).

¿Cuál era la naturaleza de estos "ministros de paz"? Los documentos no permiten responder a esta pregunta con exactitud. Sin embargo, puede observarse que en la comisión propuesta por Pombo estarían representados el comercio, la hacienda, la justicia y hasta la soberanía de la nación española, puesto que Antonio de Narváez había sido elegido diputado del Reino a la Junta Central. Semejante comitiva tenía, pues, todos los elementos necesarios para negociar verdaderamente y conseguir la reducción a la obediencia de un gobierno que se titulaba soberano y que ejercía de hecho las potestades reales. La presencia de un abogado experto en los "negocios políticos", como Gutiérrez de Caviedes, debía permitir, además, asentar los acuerdos alcanzados sobre bases firmes para que éstos no carecieran de legitimidad. La bienintencionada propuesta de José Ignacio de Pombo no gozó del beneplácito del virrey, quien la juzgó quizás demasiado generosa. Sin embargo, Amar y Borbón consideró y adaptó su idea de mediación, y a comienzos de octubre designó como ministro de paz a José María Lozano, en consorcio con Ignacio Tenorio y el obispo de Cuenca $^{19}$. No obstante, las providencias que acompañaron esta medida hacían que las posibilidades reales de obtener algún resultado fueran mínimas.

El historiador José Manuel Groot refiere que Amar y Borbón, irresoluto hasta el extremo, quiso contemporizar con los dos partidos que surgieron alrededor de la cuestión quiteña, tomando providencias opuestas, la una de paz y la otra de guerra (2: 179-80). En efecto, al tiempo que dirigió a Quito, "en clase de comisionado pacificador", al marqués de San Jorge, José María Lozano, despachó también 300 fusileros de línea. En Santafé, no bien se observó la disminución de la fuerza armada, creció la fermentación, y con ella la osadía de los pasquines y las cartas sediciosas, hasta el punto de que el virrey, según afirmó después, se vio precisado, "como si estuviera en país enemigo, a pasar muchas noches en vela, y sobre las armas la poca tropa que me restaba". La incertidumbre se prolongó durante veinte días, tiempo que necesitarían los refuerzos procedentes de Cartagena para entrar a la capital (AGI, $S F$ 629).

\footnotetext{
${ }^{19}$ En carta al virrey (7 de octubre de 1809), José María Lozano solicitó para emprender su misión dos soldados de caballería que lo acompañaran y custodiaran, y 4.000 o 6.000 pesos para gastos de viaje y hacer algunas expensas "que acaso serán necesarias para captarme la benevolencia de aquellas personas con quienes voy a tratar". Así mismo pidió que se ordenase a los gobernadores de Panamá, Popayán y Cuenca que auxiliasen sus pacíficas negociaciones (AGN, $H$ 5, ff. 308-313 v).
} 
El envío del comisionado pacificador, resultó ser puramente ceremonial, no sólo por la ya anotada remisión de tropa, sino también porque fue detenido por el gobernador de Popayán, Miguel Tacón. Éste, según refirió posteriormente el comisario regio Antonio de Villavicencio, "le puso centinelas a pretexto de que no se le presentó a su paso por la ciudad de Pasto, no obstante hallarse dicho Tacón ausente, y haberlo hecho con su pasaporte ante el alcalde ordinario, el citado Lozano, y ser tan urgente su comisión que no debía detenerse, ni el gobernador tampoco mezclarse en ella" (AGI, SF 629) ${ }^{20}$.

En síntesis, las autoridades tan sólo estaban buscando ganar tiempo con el despacho de un ministro de paz. Todo indica, en efecto, que nunca fue su intención entrar en negociaciones con los rebeldes. Desde comienzos de septiembre habían sido dictadas las providencias necesarias para imponerles un estricto bloqueo, vigilando los pasos y caminos en Cuenca, Guayaquil y Popayán; arrebatándoles el control del puerto de Carondelet e impidiendo la comunicación con el Marañón, por los ríos Napo, Curabay y Putumayo (AGN, $H$ 5, ff. 252, 295-296 y 307) ${ }^{21}$. Como si esto fuera poco, al recibirse noticias de la entrada de las tropas de Lima, se ordenó a los comisionados suspender las negociaciones de paz: Ignacio Tenorio permaneció, en consecuencia, en Popayán, mientras que el marqués de San Jorge, no bien llegó a Quito, hubo de emprender, desairado, el camino de retorno (AGI, $S F$ 657).

Cuando el cabildo de Cartagena recibió el oficio del marqués de Selva Alegre, era ya demasiado tarde. Sin duda, sus miembros estaban al tanto de las providencias hostiles de los virreyes y consideraban muy remota la posibilidad de éxito de los quiteños. Además, conocían las noticias de Santafé y sabían que allí la revolución no había germinado. En consecuencia, es apenas lógico el acuerdo del 3 de octubre, mediante el cual se decidió la manera en que había de contestarse al presidente de la Junta y se encargó a Antonio José de Ayos la redacción del oficio. Fundamentalmente, los cartageneros, a pesar mostrarse convencidos de las buenas intenciones y del patriotismo de los quiteños, reprobaban las grandes mudanzas, capaces de producir divisiones funestas en el seno de la Monarquía (Jiménez 1: 51-59).

\footnotetext{
${ }^{20}$ El "Oficio de Antonio Villavicencio a los señores Lardizábal y Primer Secretario de Estado y del Despacho" (Cartagena, 24 de mayo de 1810) fue publicado en el Boletín Historial (1, cuaderno 12: 456). Véase, igualmente, el "Suplemento al Diario Político número 6".

${ }^{21}$ El 12 de octubre el virrey reiteraba al gobernador Miguel Tacón que mientras llegaban las tropas debía "contemporizar, sostenerse y mantener del modo posible la seguridad de los lugares de su jurisdicción".
} 


\section{FRONTERAS}

de la historia

No obstante, la contestación del ayuntamiento cartagenero no debe llamar a engaños. Algunos indicios demuestran que el establecimiento de la Junta de Quito contribuyó a aumentar la fermentación en la provincia. Así, por ejemplo, el teniente coronel de ingenieros Vicente Talledo aseguraba al virrey en noviembre que los capitulares de Mompox se habían propuesto imitar la conducta de los quiteños, estableciendo un gobierno similar en aquella villa (Corrales 1: 20-21).

También en la Provincia de Antioquia se recelaba grandemente un contagio, como lo demuestra el proceso incoado por las autoridades de la villa de Medellín a fines de diciembre. Para la festividad de los Santos Inocentes algunos jóvenes se habían propuesto realizar una mascarada en la que debía representarse la prisión de Fernando VII por Napoleón Bonaparte. La mojiganga era tanto más peligrosa por cuanto había sido concebida, entre otros, por los hijos de José María de Salazar (sobrino del abogado Juan de Dios Morales, cabecilla de los insurgentes de Quito) y por Vicente Nariño, hijo de Antonio, el temido revolucionario de Santafé (AHM, CM 75, ff. 274-308).

El seísmo de Quito tuvo, pues, en el Nuevo Reino algunas réplicas. Sin embargo, en ningún lugar fueron éstas tan importantes como en la capital virreinal, donde provocó gran fermentación. Según denunció la audiencia, después de los congresos del 6 y el 11 de septiembre el ayuntamiento había solicitado con insistencia la instalación de una junta. Circularon pasquines y anónimos en los que se acusaba de bonapartismo a los funcionarios reales y se denunciaba su propósito de entregar el Reino a los franceses. En diciembre Luis Caicedo acusó a Amar y Borbón de mantener correspondencia con ellos y de ser negligente en lo relativo a la defensa del Reino; luego le formó sumaria con declaración de diversos testigos y la envió al Consejo de Regencia. Según los declarantes, el oidor Hernández de Alba pretendía apoderarse del mando y había proyectado el asesinato del virrey por haber sorprendido sus comunicaciones con el enemigo (AGI, $S F$ 746). ¿Eran estas acusaciones fundadas, o se trataba sencillamente de ardides para conseguir la erección de una junta como las de la Península? ¿Puede darse crédito a esta versión, o debe verse en ella, por el contrario, un intento por desvanecer onerosas sospechas? Imposible determinar este punto.

Lo cierto es que para contener las novedades y desvanecer los peligros, la Audiencia se propuso neutralizar al motor de las novedades, esto es, al Cabildo, y para ello aconsejó al virrey que nombrase seis regidores añales con un pretexto fútil. De ese modo serían manipuladas las elecciones que se avecinaban 
y, en consecuencia, los principales empleos de república (alcaldes ordinarios, síndico procurador y asesor del cabildo) recaerían en personas de reconocida fidelidad. Sin embargo, a pesar de tener efecto los nombramientos arbitrarios, el pulso lo ganó el Cabildo, que consiguió elegir, mediante intrigas, a conspicuos miembros de su partido (AGI, $S F$ 746).

A finales del año denunciose una conspiración proyectada por Antonio Nariño, Luis Caicedo, Baltasar Miñano y Andrés Rosillo ${ }^{22}$. Con el fin de instalar una Junta en la capital, los facciosos se habían propuesto cohechar las tropas y levantar el pueblo con el falso supuesto de que se preparaba una masacre contra los criollos. La audiencia logró conjurar la sedición formando causa y decretando la prisión de los tres principales novadores. En representación al Consejo de Regencia, uno de los oidores se dolería posteriormente de la debilidad de carácter del virrey, que había impedido llevar a la cárcel a la totalidad de los comprometidos (AHR, FI 4, ff. 495 y ss).

$\mathrm{Si}$, como se ha visto, la revolución del 10 de agosto tuvo un influjo notable en el Nuevo Reino, éste resultó insuficiente para suscitar la erección de una junta en Santafé ${ }^{23}$. No obstante, a principios de 1810 la situación en la capital virreinal era crítica. Harto conscientes de ello, las autoridades esperaban con ansias la llegada de los comisionados regios, confiando que ellos lograrían apagar el incendio general que amenazaba al Reino.

Los miembros de la Junta de Quito esperaban que su iniciativa fuera imitada por todo el continente. En las capitales de los virreinatos y capitanías generales, los funcionarios reales debían ser remplazados por gobiernos que, a semejanza de las juntas peninsulares del año anterior, reasumieran interinamente la soberanía. Por formar parte de la misma nación, todos ellos habían de confederarse para combatir efectivamente al emperador de los franceses y preservar los derechos de Fernando VII. Tales serían, en principio, las razones de la unión.

¿Qué sucedería en caso de que fuera imposible el retorno del rey? ¿Qué tipo de nexos debían constituir los diferentes estados en caso de una total subyugación de la Península? Estos interrogantes, que sin duda fueron formulados por los vocales de la Junta de Quito - convencidos como estaban del triunfo de los franceses-, no pueden ser respondidos. Las noticias de la revolución del 10 de agosto, lejos de desencadenar un movimiento continental, provocaron la alerta

\footnotetext{
${ }^{22}$ El proceso fue publicado por Enrique Ortega Ricaurte (1-22).

${ }^{23}$ Para una interpretación similar a la que aquí se ha hecho, véase Robert L. Gilmore.
} 


\section{FRONTERAS}

de la historia

Vol.12 / 2007

de las autoridades, que extremaron las medidas de vigilancia. En Lima y Santafé, virreyes y oidores no sólo frustraron cualquier ímpetu subversivo, sino que además dirigieron la máquina guerrera que puso fin a la Junta Suprema de Quito.

\section{La alianza con los ingleses}

El gobierno revolucionario era consciente de la necesidad de trabar relaciones con las naciones extranjeras. No hay que olvidar que uno de sus principales propósitos era defender el reino de los ataques de Napoleón. ¿Cómo podía Quito por sí sólo triunfar contra el ejército francés que se había paseado victorioso por toda Europa? Ya se ha señalado que los juntistas pretendían crear una alianza con los demás gobiernos que surgieran en América como consecuencia de la crisis de la nación. Sin embargo, aquel plan era insuficiente para contener al "tirano de la Europa". ¿Quién si no Inglaterra podía ayudar a los revolucionarios a ponerse en pie de guerra? Además de ser la única nación capaz de oponerse a los planes de Napoleón, su poderío naval le permitía estar presente en todos los mares del mundo.

Los quiteños necesitaban, además, armas y municiones con urgencia, no sólo para defenderse de una eventual invasión extranjera, sino también para contrarrestar las agresiones del Perú y el Nuevo Reino de Granada: según el testimonio de un oficial capturado en Pasto, los rebeldes no disponían más que de 12 cañones y 700 fusiles "contando los estropeados" (AHR, FI 25, f. 111v.). Por último, el estado de bloqueo que padecía la Junta hacía necesario el establecimiento de relaciones comerciales para proveerse de los recursos que le negaban sus proveedores habituales.

Sin embargo, ni La Tola podía compararse con Cartagena, La Guaira o Veracruz, ni el océano Pacífico era el mar Caribe. Ello explica que Selva Alegre dirigiera un oficio el 14 de septiembre al "capitán de cualquier buque inglés". Se trataba de una desesperada tentativa de conseguir un agente que sirviera de intermediario comercial y político:

Señor capitán:

Enemigos eternos del infame devastador de la Europa, Bonaparte, hemos resuelto resistir hasta la muerte á su tiranía, como lo ha hecho la gloriosa e incomparable nación inglesa. En su virtud el pueblo de este Reino ha separado del mando de él a los españoles que lo regían, sospechados de secuaces declarados de aquel monstruo, y ha creado una Junta Suprema Gubernativa [...]. 
Por tanto, yo como su presidente y a nombre de la misma, pido a usted armas y municiones de guerra que necesitamos, principalmente fusiles y sables. Sírvase usted traernos a cualquiera de los puertos de Atacames o Tola, dos mil fusiles, con sus bayonetas y dos mil sables de munición, pues serán satisfechos a los precios corrientes.

Apetece íntimamente esta Suprema Junta la más estrecha unión y alianza con su inmortal nación y la franquicia de nuestro comercio con ella. Sírvase usted proporcionarnos estas ventajas, poniendo nuestra intención y deseos en noticia de los comandantes de sus islas del sur, a quienes suplicamos se dignen pasar la misma al gabinete de San James y al augusto Monarca de los Mares. (AGN, H 5, f. 666.)

La maniobra del gobierno revolucionario de Quito se inspiraba en las acciones de las juntas peninsulares de 1808, que a imagen de las de Asturias y Galicia habían entrado en contacto con las autoridades inglesas y habían conseguido enviar sus diputados a Londres, gracias al concurso de los corsarios (Lagüens 14; Villa-Urrutia 104-05).

Para que la tentativa tuviera éxito, el marqués de Selva Alegre envió instrucciones al teniente de Carondelet (14 de septiembre), ordenándole que diera puerto y auxiliara a los ingleses que se le presentaran. Entre tanto, lo instaba a pasar cuanto antes a Tumaco en busca de algún buque de esa nación. En caso de hallar alguno, debía entrar en contacto con su capitán y comprarle todos los fusiles que tuviera a bordo. A continuación había de encargarle cuantas armas pudiera acarrear de las Galápagos o demás establecimientos que tuvieran los ingleses en el sur (AGN, H 5, f. 684). Desgraciadamente para los juntistas, las instrucciones de Selva Alegre no podían rendir fruto alguno, pues cuatro días antes de haber sido escritas, las tropas enemigas se habían apoderado de la población de Carondelet y del puerto de La Tola ${ }^{24}$.

Tal como sucedió con la búsqueda de la obediencia de las provincias circunvecinas o con los intentos de conformación de una alianza con Lima y Santafé, las gestiones de la Junta Suprema de Quito tendientes a conseguir una alianza con los ingleses fracasaron. Un negocio tan dilatado como ése difícilmente podía ser concluido por un gobierno frágil, inestable y acosado por la guerra. El licenciado Juan de Dios Morales lamentaría desde la cárcel que se

\footnotetext{
${ }^{24}$ El expediente sobre la toma del puerto de La Tola se encuentra en AGI $(Q 384)$. Véase también el oficio que Miguel Tacón remitió el 6 de octubre de 1809 al teniente gobernador de Tumaco José Nicolás (AGN, H 5, f. 307).
} 


\section{FRONTERAS}

de la fistoria

hubiesen frustrado las medidas adoptadas por la Junta con el fin de convertir al inglés en "potente protector y aliado generoso" de los quiteños. Según indicó entonces el antiguo ministro, los acercamientos habían estado igualmente encaminados a hacer una manifestación vigorosa contra los planes de Napoleón con el fin de disuadir a la Gran Bretaña de emprender cualquier conquista de la América Meridional (AGN, H 5, f. 197v.).

Como se ve por el testimonio citado, la voluntad de mantener la independencia de los reinos americanos, en caso de total subyugación de la Península, significaba no sólo contrariar las ambiciones de la "potencia dominante" (Francia), sino también las que pudiera manifestar la "potencia rival" (Inglaterra), de acuerdo con los términos empleados por Gabriel Bonnot de Mably (cap. 5). La protección de Gran Bretaña debía permitir al Reino de Quito - que se hallaba prácticamente en estado de indefensión - preservar su autonomía y resistir con éxito a la codicia de las naciones europeas. No en vano la corona de Portugal había manifestado ya abiertamente sus pretensiones sobre los territorios españoles en América, en virtud del matrimonio del príncipe heredero con la infanta Carlota.

\section{Conclusiones}

Como se ha visto, pueden distinguirse tres niveles en las políticas exteriores de la Junta de Quito: en primera instancia, el de las provincias correspondientes al espacio del que se sentía cabeza natural; en segundo lugar, los reinos americanos que debían crear gobiernos autónomos como consecuencia de los triunfos napoleónicos, y por último, las naciones extranjeras. Cada uno de estos niveles exigía una atención particular y medios específicos. La existencia de nexos de dependencia como los de la Audiencia de Quito autorizaba, en principio, las incorporaciones. Sin embargo, éstas no podían conseguirse sin una negociación basada en el ofrecimiento de prebendas, la abolición de impuestos y una representación en el gobierno. La abdicación del ideal autonómico sólo podía obtenerse a cambio de privilegios.

Entre tanto, las relaciones con otras capitales americanas, que tenían por naturaleza el derecho de convocar cortes y constituir juntas, debían establecerse en términos muy distintos. La lucha común contra Napoleón y la necesidad de mantener la paz y contener las conquistas llevaban naturalmente a la constitución de lazos confederativos. 
En cuanto a la diplomacia exterior, apenas esbozada en el caso quiteño, cabe decir que estaba dirigida sobre todo a la obtención de recursos y a la búsqueda de protección y aliados espontáneos. Gran Bretaña, por supuesto, se impuso desde entones como el candidato ideal. Los esfuerzos para atraerse sus favores serían mucho más consistentes a partir de 1810. Lo dicho es áalido para los gobiernos neogranadinos, pero sobre todo para Venezuela.

Este esquema tripartito que acaba de referirse en lo tocante a las relaciones exteriores, se hallará también durante los años 1810-1815 en el Nuevo Reino de Granada. Entonces, y como en el caso quiteño, las provincias desconocerían las pretensiones hegemónicas de la capital y lejos de contentarse con obedecer exigirían el reconocimiento de su soberanía e independencia. Así pues, la diplomacia provincial o constitutiva, que en 1809 en Quito no pasó de buenas intenciones, conocería en el Nuevo Reino un desarrollo excepcional.

\section{Bibliografía}

\section{Fuentes primarias}

\section{$\underline{\text { Archivos }}$}

Archivo General de Indias, Sevilla, España (AGI).

Santa Fe (SF) 629, 657, 746 y 960.

Quito $(Q) 234,235,252$ у 269.

Archivo General de la Nación, Bogotá, Colombia (AGN).

Sección Archivo Anexo, Historia (H) 4-6, 11 y 15.

Archivo Histórico de Antioquia, Medellín, Colombia (AHA).

Independencia (I) 816.

Archivo Histórico de Medellín, Medellín, Colombia (AHM).

Concejo de Medellín (CM) 75.

Archivo Histórico Restrepo, Bogotá, Colombia (AHR). 


\section{FRONTERAS}

de la historia

Vol.12 / 2007

Fondo $I(F I) 4$ y 25.

\section{Fuentes primarias}

“Acusación del Fiscal Tomás de Arechaga, en la causa seguida contra los Patriotas del 10 de Agosto de 1809 pocos días antes de la inmolación de aquellos". Museo Histórico. Órgano del Museo de Historia 6.19 (1954).

Bonnot de Mably, Gabriel. Principes des négociations pour servir d'introduction au droit public de l'Europe, Introduction et notes de Marc Belissa. París: Éditions Kimé, 2001.

"Carta del Marqués de Villa Orellana a su tío el doctor don Julián Francisco Cabezas" (21 de agosto de 1809). Boletín de la Sociedad Ecuatoriana de Estudios Históricos Americanos 3.6 (s. f.).

"Confesión del doctor don Manuel Rodríguez de Quiroga, abogado de esta Real Audiencia". Museo Histórico, Órgano del Museo de Historia 2.5 (1950): 18-40.

"Documentación acreditada por el obispo de Cuenca, don Andrés Quintián Ponte, acerca del movimiento de Independencia de Quito". Boletín de la Academia Nacional de Historia 17.70 (s. f.).

Corrales, Manuel Ezequiel, comp. Documentos para la historia de la Provincia de Cartagena de Indias, hoy Estado Soberano de Bolivar, en la Unión Colombiana. 2 t. Bogotá: Imprenta de Medardo Rivas, 1883.

Laspra Rodríguez, Alicia, ed., transcripción y trad. Las relaciones entre la Junta General del principado de Asturias y el Reino Unido de Gran Bretaña e Irlanda en la guerra de la Independencia. Repertorio documental. Oviedo: Junta General del Principado de Asturias, 1999.

"Manifiesto al público" (Quito, agosto 10 de 1809). Antonio Villavicencio (el protomártir) y la Revolución de Independencia, J. D. Monsalve. T. 1. Bogotá: Academia Colombiana de Historia, 1920. 328-30.

Martínez Delgado, Luis y Sergio Elías Ortiz, eds. El periodismo en la Nueva Granada. Bogotá: Academia Colombiana de Historia, 1960. 
"Oficio de don Salvador Murgueytio y D. Pedro Calisto al obispo de Cuenca". Boletin de la Academia Nacional de Historia 17.70 (s. f.): 233-88.

Ortega Ricaurte, Enrique, comp. Documentos sobre el 20 de julio de 1810. Bogotá: Academia Colombiana de Historia, 1960.

Padilla, Fray Diego Francisco. Motivos que han obligado al Nuevo Reyno de Granada á reasumir los derechos de la Soberanía, remover las Autoridades del antiguo Gobierno, è instalar una Suprema Junta baxo la sola denominación y en nombre de nuestro Soberano Fernado VII y con independencia del Consejo de Regéncia, y de qualquiera otra representación. Santafé: s. e., 1810.

Palacio Fajardo, Manuel. Révolutions de l'Amérique Espagnole, ou récit de l'origine, des progrès et de l'état actuel de la guerre entre l'Espagne et l'Amérique méridionale. Par un citoyen de l'Amérique Espagnole. Traduit de l'anglais. Deuxième édition revue, corrigée et augmentée du précis des événemens survenus en Amérique depuis la fin de 1816 jusqu'à ce jour ; de la constitution des provinces unis de l'Amérique du sud; de notices biographiques sur les principaux chefs des indépendants; et ornée d'une belle carte générale de l'Amérique, tracée d'après les dernières divisions, par M. Delamarche. París: Librairie Universelle de P. Mongie l'aîné, 1819.

Rodríguez Piñérez, Eduardo, ed. La vida de Castillo y Rada. Bogotá: Academia Colombiana de Historia, 1949.

Wicquefort, Abraham de. L'Ambassadeur et ses fonctions. T. 1. Amsterdam : Chez les Janssons a Waesberge, 1730.

\section{Fuentes secundarias}

Belissa, Marc. Fraternité universelle et intérêt national (1713-1795). Les cosmopolitiques du droit des gens. París: Kimé, 1998.

Cavelier, Germán. La política internacional de Colombia. Un ensayo de interpretación. Primera parte La Gran Colombia (1820-1830). Bogotá: Iqueima, 1949. 


\section{FRONTERAS}

de la historia

Vol.12 / 2007

Deler, Jean Paul. Ecuador, del espacio al estado nacional. Quito: Banco Central del Ecuador, 1987.

Demélas, Marie-Danielle. L’invention politique. Bolivie, Équateur, Pérou au XIX $X^{e}$ siècle. París: Recherche sur les Civilisations, 1992.

Gilmore, Robert L. "The Imperial Crisis, Rebellion, and the Viceroy: Nueva Granada in 1809". Hispanic American Historical Review 40.1 (1960): $1-24$.

Groot, José Manuel. Historia eclesiástica y civil de Nueva Granada, escrita sobre documentos auténticos por don José Manuel Groot. 3 t. Bogotá: Foción Mantilla, 1869.

Gutiérrez Ardila, Daniel. 'La diplomacia 'constitutiva' en el Nuevo Reino de Granada (1810-1816)”. Historia Crítica 33 (2007).

Gutiérrez Ponce, Ignacio. Vida de Don Ignacio Gutiérrez Vergara y episodios históricos de su tiempo (1806-1877) por su hijo Ignacio Gutiérrez Ponce. T. 1. Londres: Bradbury, Agnew \& Cía., 1900.

Jiménez Molinares, Gabriel. Los mártires de Cartagena de 1816 ante el consejo de guerra y ante la historia. 2 t. Cartagena: Imprenta Departamental, 1947-1950.

Jijón y Caamaño, Jacinto. Quito y la Independencia de América. Quito: Academia Nacional de Historia, 1922.

Hocquellet, Richard. "Fragments d'un discours politique: la diffusion de la presse patriotique espagnole en Amérique (1808-1810)". L'Amérique Latine et les modèles européens. Eds. Annick Lempérière et al. París: L'Harmattan, 1998. 47-78.

Lagüens, Gerardo. Relaciones internacionales de España durante la guerra de Independencia. Zaragoza: Centro Superior de Investigaciones Científicas, 1959.

Landázuri, Carlos. "La independencia del Ecuador 1808-1822". Nueva Historia del Ecuador. T. 6. Ed. Enrique Ayala. Quito: Corporación Editora Nacional, 1989. 
—. "Las primeras juntas quiteñas". La independencia en los países andinos: nuevas perspectivas. Eds. Guillermo Bustos y Armando Martínez. Bucaramanga: UIS, 2004.

McFarlane, Anthony. Colombia antes de la Independencia. Economía, sociedad y política bajo el dominio Borbón. Bogotá: Banco de la República; El Áncora, 1997.

Monsalve, J. D. Antonio de Villavicencio (el protomártir) y la Revolución de Independencia. 2 t. Bogotá: Academia Colombiana de Historia, 1920.

Morelli, Federica. Territoire ou nation? Reforme et dissolution de l'espace impérial. Équateur 1765-1830. París: L’Harmattan, 2004 [Ed. cast. Territorio o nación: reforma y disolución del espacio imperial en Ecuador, 1765-1830. Madrid: Centro de Estudios Políticos y Constitucionales, 2005].

Phelan, John Leddy. The Kingdom of Quito in the Seventeenth Century. Bureaucratic Politics in the Spanish Empire. Madison: The University of Wisconsin Press, 1967.

Ramírez de Villa-Urrutia, Wenceslao. Relaciones entre España é Inglaterra durante la guerra de Independencia. Apuntes para la historia diplomática de España de 1808 a 1814. T. 1. Madrid: Librería de F. Beltrán Príncipe, 1911.

Ramos Pérez, Demetrio. Entre el Plata y Bogotá. Cuatro claves de la emancipación ecuatoriana. Madrid: Centro Iberoamericano de Cooperación, 1978.

Restrepo, José Manuel. Historia de la revolución de la República de Colombia en la América Meridional. T. 1. Besançon: Joseph Jacquin, 1858.

Rivas, Raimundo. Historia diplomática de Colombia (1810-1934). Bogotá: Ministerio de Relaciones Exteriores, 1961.

Rodríguez, Jaime. "Las primeras elecciones constitucionales en el Reino de Quito, 1809-1814”. Procesos 14 (1999). 


\section{FRONTERAS}

de la fistoria

Vol.12 / 2007

- La revolución política durante la época de la Independencia. El Reino de Quito 1808-1822. Quito: Universidad Andina Simón Bolívar, 2006.

Terán Najas, Rosemarie. Los proyectos del imperio borbónico en la Real Audiencia de Quito. Quito: Abya Yala, 1988.

Torre Reyes, Carlos de la. La revolución de Quito del 10 de agosto de 1809. Quito: Banco Central del Ecuador, 1990.

Urrutia, Francisco José. Los Estados-Unidos de América y las repúblicas hispano-americanas de 1810 a 1830. Páginas de historia diplomática. Madrid: América, 1918.

Villa-Urrutia, W.R. Relaciones entre España é Inglaterra durante la guerra de independencia. Apuntes para la historia diplomática de España de 1808 a 1814. T. 1. Madrid: Librería de F. Beltrán Príncipe, 1911.

Zubieta, Pedro A. Apuntaciones sobre las primeras misiones diplomáticas de Colombia (primero y segundo periodos 1809-1819-1830). Bogotá: Imprenta Nacional, 1924.

Fecha de recepción: $1^{\circ}$ de abril de 2007.

Fecha de aprobación: 30 de julio de 2007. 